\title{
The functional and surgical relevance of the iliocapsularis muscle: an anatomical review
}

\author{
Faizullah Mashriqi ${ }^{1}$, Anthony V. D'Antoni ${ }^{2}$, Charlotte Wilson ${ }^{3}$, Florence Unno ${ }^{4}$, Cara Beth Lee ${ }^{4}$, \\ Keith $\mathrm{Mayo}^{3}$, R. Shane Tubbs ${ }^{3,5}$ \\ ${ }^{1}$ Department of Molecular, Cellular, and Biomedical Sciences, CUNY School of Medicine, New York, NY, USA \\ ${ }^{2}$ Division of Anatomy, Department of Radiology, Weill Cornell Medical College, New York, USA \\ ${ }^{3}$ Seattle Science Foundation, Seattle, WA, USA \\ ${ }^{4}$ Swedish Hip and Pelvis Center, Swedish Medical Group, Seattle, WA, USA \\ ${ }^{5}$ Department of Anatomical Sciences, St. George's University, Grenada, West Indies
}

\begin{abstract}
The iliocapsularis muscle covers the anterior aspect of the hip joint capsule. Although its anatomy has been described through cadaveric and radiologic studies, its true function is unknown. The iliocapsularis could be involved in preventing anterior synovial impingement, a possibility supported by electromyography studies. Moreover, hypertrophy of the iliocapsularis caused by hip dysplasia supports the proposal that it stabilizes the anterior aspect of the joint capsule. This review discusses the clinical relevance of the iliocapsularis.
\end{abstract}

Keywords: hip dysplasia; iliocapsularis; iliacus minor; iliotrochantericus; rectus femoris; stability

Anatomy 2017;11(3):146-148 (2017 Turkish Society of Anatomy and Clinical Anatomy (TSACA)

\section{Introduction}

The iliocapsularis muscle (Figure 1), also referred to as the iliacus minor or iliotrochantericus, is a muscle over the human hip just deep to the rectus femoris. It originates from the anterior inferior iliac spine and the anteromedial hip joint capsule and inserts on to the lesser trochanter. ${ }^{[1-4]}$ Although the iliocapsularis is apparently constant in humans, the literature fails to describe it in detail. Interestingly and comparatively, it has been found in primates, rats, reptiles, and birds. ${ }^{[1]}$

Although the anatomy of the iliocapsularis has been described, its true function is disputed. Multiple functions have been proposed and supported in the literature. Additionally, the iliocapsularis has been used as an important surgical landmark in procedures involving the hip joint capsule. Moreover, studies have shown that understanding its radiological appearance is important in categorizing pathologies of the hip (e.g., hip dysplasia).

\section{Functional Relevance}

Although hypotheses have been proposed, the true function of the iliocapsularis has not been elucidated. It was first mentioned in 1843 by the French anatomist Jean Cruveilhier, who suspected the muscle acted as a stabilizer to the femoral head; however, he offered no explanation as to how this might be achieved. ${ }^{[5,6]}$ Some propose that the iliocapsularis helps to prevent synovial impingement on the anterior aspect of the joint capsule. ${ }^{[2]}$ This accords it a similar function to the articularis genus of the knee joint. In principle, the iliocapsularis would prevent impingement during hip flexion by creating tension in the joint capsule. ${ }^{[3]}$

Many agree that the iliocapsularis contributes to stabilizing the anterior hip joint. ${ }^{[1-4]}$ This is possible via its tightening action on the joint capsule. In cases of hip dysplasia, the iliocapsularis would be hypertrophied owing to the extra force needed to stabilize the femoral head in the dysplastic acetabulum. ${ }^{[1]}$ In fact, iliocapsularis-to-rectusfemoris size ratios (width, thickness, cross-sectional area, and circumference) can be used to identify borderline hip dysplasia. ${ }^{[4]}$ Haefeli et al. ${ }^{[4]}$ demonstrated that these ratios are all increased in patients with developmental dysplasia of the hip joint. Therefore, they can be used to direct treatment in borderline hip dysplasia. 
Because of the deep location of the iliocapsularis, electromyography (EMG) has only recently been successfully recorded for it. ${ }^{[3]}$ EMG provides insight into muscle activation, which can potentially elucidate muscle function. Lawrenson and colleagues ${ }^{[3]}$ placed EMG electrodes in the iliocapsularis under ultrasound guidance. The electrode was passed through the sartorius muscle, lateral to the femoral artery and medial to tendon of the rectus femoris. Coursing in a slightly medial direction, the electrode then penetrated the iliacus and finally the iliocapsularis. The maximum iliocapsularis activity was documented during resistance to hip flexion $>90^{\circ}$, and the minimum during hip extension from the neutral position $\left(0^{\circ}\right) .^{[3]}$

As previously mentioned, one proposed function of the iliocapsularis is to prevent synovial impingement during flexion. The maximal EMG activity during hip flexion at $>90^{\circ}$ supports this proposal. The iliocapsularis has also been proposed to function as a stabilizer of the anterior joint capsule. If this is true, the muscle would prevent anterior translation of the femoral head and maintain joint stability during hip extension. However, EMG activity for it was minimal during hip extension from the neutral position. Lawrenson et al. ${ }^{[3]}$ suggested that the iliocapsularis could still provide stability in other regions of the capsule.

\section{Surgical Relevance}

Owing to its location, the iliocapsularis is used as a surgical landmark in many procedures. During a modified Smith-Peterson approach to a Bernese periacetabular osteotomy for hip dysplasia, the iliocapsularis is used to expose the anteromedial aspect of the hip joint capsule. ${ }^{[1,2,7]}$ Elevation of it allows for entrance into the correct interval between the iliopsoas tendon and the hip capsule. ${ }^{[5]}$ The iliocapsularis is also used to identify the iliopsoas tendon during tenotomies from either the anterolateral or lateral directions. During complete hip arthroplasty, the lateral aspect of the iliocapsularis is commonly used as the location for capsulotomy. ${ }^{[1,2]}$ Using the intermuscular space between the inserting fibers of the gluteus minimus and the iliocapsularis as landmarks ensures a precise T-capsular incision while avoiding injury to these muscles and tendons and to the vascular supply to the hip. ${ }^{[8]}$

\section{Imaging}

The iliocapsularis can be visualized by both magnetic resonance imaging (MRI) and ultrasound; however, clinicians rarely recognize it as a structure distinct from the iliacus muscle. ${ }^{[2]}$ To visualize the iliocapsularis with ultrasonography, the patient should be in the supine position with an

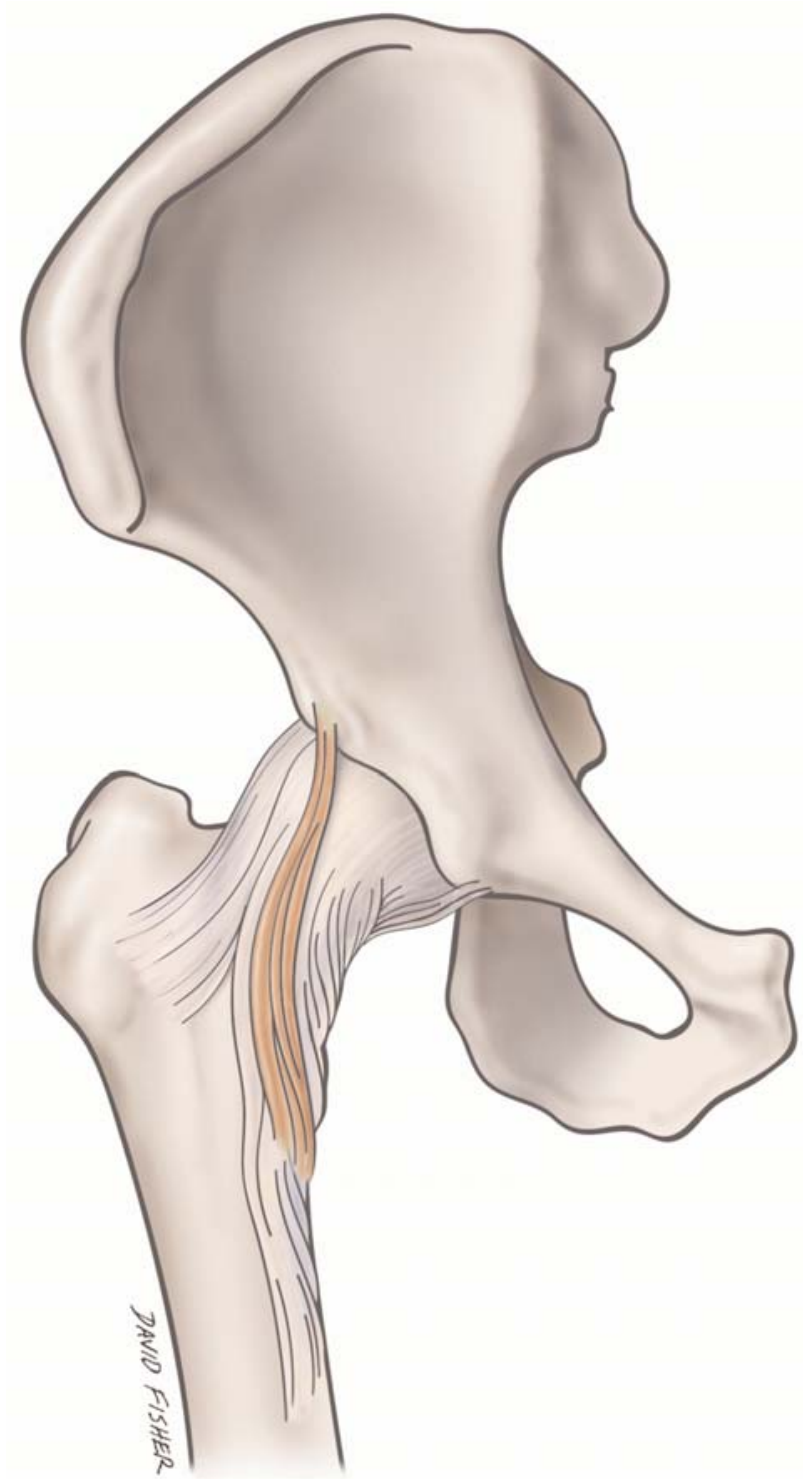

Figure 1. Schematic drawing of the right iliocapsularis muscle. Note its attachement from the anterior inferior iliac spine proximally to the anterior joint capsule inferiorly. [Color figure can be viewed in the online issue, which is available at www.anatomy.org.tr]

externally rotated hip. The ultrasound transducer should be placed inferior to the anterior inferior iliac spine in the transverse plane. This region marks the origin of the iliocapsularis. By moving the transducer caudally, the insertion onto the lesser trochanter is visualized. ${ }^{[2]}$ The iliocapsularis is best visualized with MRI using axial slices through the femoral head. It lies just superficially and laterally to the joint capsule. The rectus femoris is visualized superficial to the iliocapsularis. As Haefeli et al. ${ }^{[4]}$ discuss, the size ratio between these two muscles can be used to identify borderline hip dysplasia. 


\section{Conclusion}

The iliocapsularis is a constant muscle on the anterior aspect of the hip joint capsule. It is believed to stabilize the hip joint. Hypertrophy of the iliocapsularis with hip dysplasia supports this belief. It could also be involved in preventing synovial impingement as the articularis genus does in the knee. Regardless of function, the iliocapsularis is used a key landmark in multiple surgeries including hip arthroplasty, iliopsoas tendon tenotomy, and Bernese periacetabular osteotomy. It can be visualized in both ultrasonography and MRI although clinicians rarely distinguish it from the iliacus muscle.

\section{References}

1. Babst D, Steppacher SD, Ganz R, Siebenrock KA, Tannast M. The iliocapsularis muscle: an important stabilizer in the dysplastic hip. Clin Orthop Relat Res 2011;469:1728-34.
2. Pourcho AM, Sellon JL, Lachman N, Krych AJ, Smith J. Sonographic appearance of the iliocapsularis muscle of the hip. PM R 2015;7:94-6.

3. Lawrenson P, Grimaldi A, Crossley K, Hodges P, Vicenzino B, Semciw AI. Iliocapsularis: technical application of fine-wire electromyography, and direction specific action during maximum voluntary isometric contractions. Gait Posture 2017;54:300-3.

4. Haefeli PC, Steppacher SD, Babst D, Siebenrock KA, Tannast M. An increased iliocapsularis-to-rectus-femoris ratio is suggestive for instability in borderline hips. Clin Orthop Relat Res 2015;473:3725-34.

5. Ward WT, Fleish ID, Ganz R. Anatomy of the iliocapsularis muscle. Relevance to the surgery of the hip. Clin Orthop Relat Res 2000;(374):278-85.

6. Cruveilhier J. Trait d'anatomie descriptive. 2nd ed. Paris: Ancienne Maison Bechet Jeune; 1843. p. 130-1.

7. Kamath AF. Bernese periacetabular osteotomy for hip dysplasia: surgical technique and indications. World J Orthop 2016;7:280-6.

8. Bedi A, Galano G, Walsh C, Kelly BT. Capsular management during hip arthroscopy: from femoroacetabular impingement to instability. Arthroscopy 2011;27:1720-31.

Correspondence to: $R$. Shane Tubbs, PhD, PA-C, MS, BS

Seattle Science Foundation, 550 17th Avenue,

Suite 600, Seattle, WA 98122, USA

Phone: +1 2067326500

e-mail: shanet@seattlesciencefoundation.org

Conflict of interest statement: No conflicts declared.

This is an open access article distributed under the terms of the Creative Commons Attribution-NonCommercial-NoDerivs 3.0 Unported (CC BY-NCND3.0) Licence (http://creativecommons.org/licenses/by-nc-nd/3.0/) which permits unrestricted noncommercial use, distribution, and reproduction in any medium, provided the original work is properly cited. Please cite this article as: Mashriqi F, D’Antoni AV, Wilson C, Unno F, Lee CB, Mayo K, Tubbs RS. The functional and surgical relevance of the iliocapsularis muscle: an anatomical review. Anatomy 2017;11(3):146-148. 